\title{
Estimation of Alignment and Transverse Load in Multi-Bearing Rotor System
}

\author{
TOM J. CHALKO and DONG-XU LI \\ ${ }^{\mathrm{a}}$ University of Melbourne, Department of Mechanical and Manufacturing Engineering, Parkville 3052, Victoria, Australia; ${ }^{\mathrm{b}}$ General \\ Motors-Holden's Automotive Ltd., Noise and Vibration Section, 241 Salmon st., Port Melbourne, Vic. 3207, Australia
}

(Received 14 March 1994; In final form 4 April 1996)

\begin{abstract}
The paper presents a method for estimation of a multi-bearing machine alignment on the basis of measured eccentricities of the shaft in machine bearings. The method uses a linear FEM model of the rotor and the non-linear models of machine bearings. In the presented example, the non-linear models of hydrodynamic bearings are used, but it is shown, that the method could be easily applied to other types of bearings. In addition to the alignment estimation, the method allows to estimate the unknown static load in the transverse direction, reduced to the equivalent load at one or two selected nodes on the shaft. Verification of the method is presented using the model of a machine with vertical shaft supported in three pressurised hydrodynamic bearings. The method is suitable for monitoring of alignment and transverse load during the machine operation.
\end{abstract}

Keywords: Alignment, Rotordynamics, Monitoring, Hydrodynamic Bearings, Transverse Load

\section{INTRODUCTION}

The need for the estimation of multi-bearing machine alignment during its operation exists in many areas of industry, especially when the machine alignment is subject to change. Changes in alignment can occur for various reasons, for example, due to thermal effects, machine load or the deformation of the foundation structure after an earthquake. Investigations by Webster and Gibson [1977] and Hashemi [1983] have shown substantial changes in alignment arising from various aspects of operating conditions for large turbines in the power generation industry. Most turbine manufacturers have separate, experimentally verified, "cold" and "hot" alignments for their turbines and other multi-bearing machines. A number of researchers successfully incorporated bearing alignment parameters in their mathematical models of rotating machinery, demonstrating significant influence of alignment on various aspects of dynamic performance of the machine, including its stability and the unbalance response. Among them are: Hori and Uematsu [1980], Parszewski and Krodkiewski [1986], Parszewski et all [1988a], [1988b], Li [1990], and Chalko and Li [1993], [1995]. Bearing alignment parameters are also incorporated in some commercial rotordynamic packages, such as TURBINE-PAK [1992]. However, to include machine alignment parameters in rotordynamic models a reliable alignment data is required, preferably identified without stopping the 
machine. Ding [1993], Krodkiewski and Ding [1994] considered application of the non-linear mathematical model of a multi-bearing rotor system for identification of its alignment and unbalance. Mathematical model used in their method requires the elastic model of the foundation structure, which is a significant practical restriction.

This paper presents a simplified method for estimation of a multi-bearing machine alignment on the basis of measured eccentricities of the shaft in machine bearings. In addition to alignment estimation, the method also enables estimation of the transverse static load, reduced to one or two selected nodes on the shaft. Presented method assumes small oscillations of the system about the equilibrium position and does not require modelling of the elastic properties of foundation structure. The method was outlined by Chalko and $\mathrm{Li}$ [1996].

\section{THE METHOD}

\subsection{Equilibrium of the System}

In our method, we assume that the system oscillates about its equilibrium position and the oscillations are small. Under such assumptions, the equilibrium position does not depend on the system oscillations and therefore can be determined independently.

To determine the equilibrium of the system, it is sufficient to know its elastic properties and the applied static load. In the case of rotating machinery, the system could be subdivided into the following three sub-systems:

(1) elastic shaft

(2) elastic bearings

(3) elastic foundation

Elastic characteristics of these sub-systems may be linear or non-linear. Our method does not put any restrictions in this regard. In the example presented in this paper, the rotor and foundation sub-systems are considered linear, but all bearings are of the hydrodynamic type and, therefore, are strongly non-linear.
To determine the shaft alignment, it is necessary to consider a static equilibrium of the shaft, determined by the static equilibrium equations (1) for the shaft, requiring that the sum of all forces and sum of all moments of forces should be both zero:

$$
\begin{gathered}
\sum_{i} L_{i}=0 \\
\sum_{i} L_{i} z_{i}=0
\end{gathered}
$$

where, $L_{i}$ is $i$-th vector component of the transverse static load and coordinates $z_{i}$ determine the location of $L_{i}$ along the shaft. Load vectors $L_{i}$ contain all bearing reactions as well as the external static load. Each vector equation (1) represents two scalar equations, which are projections of the vector equation on $X$ and $Y$ directions in the global frame of reference in FIGURE 1.

\subsection{Alignment Estimation}

Let us consider a system containing $N_{B}$ bearings. We assume that $N_{B}>2$, since for 2 bearing systems the

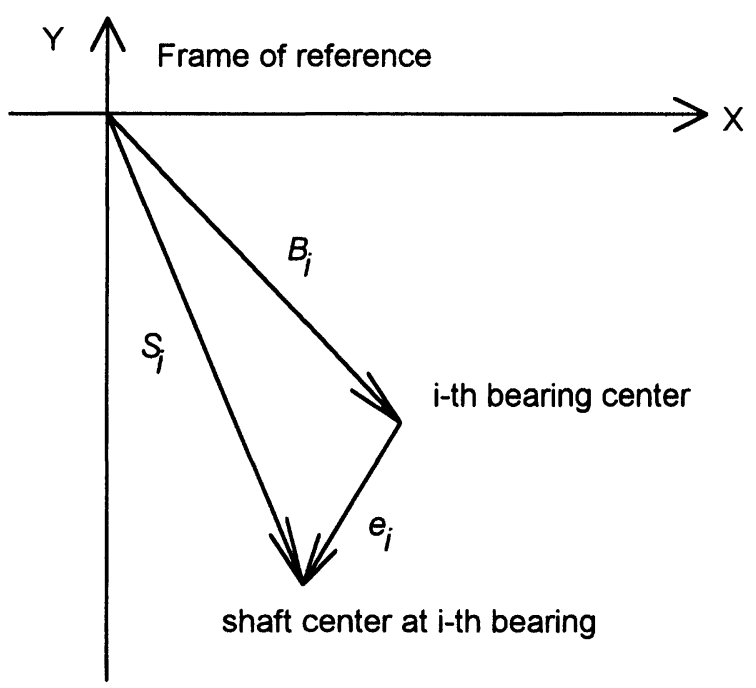

FIGURE 1 Coordinate system and alignment vectors. 
problem of alignment does not exist. To estimate the system alignment, that is the transverse positions $B_{i}$ of the bearings with respect to the fixed frame of reference, it is sufficient to know the shaft eccentricity vectors $e_{i}$ as well as the shaft deflection vectors $S_{i}$ in each bearing $\left(i=1, \ldots, N_{B}\right)$. From Fig. 1 we have:

$$
B_{i}=S_{i}-e_{i} \quad \text { for } i=1, \ldots, N_{B}
$$

In our method we assume, that we can measure shaft eccentricity vectors $e_{i}$ in corresponding bearings. In practice, when machine bearings are of the hydrodynamic type, the shaft eccentricity vectors $e_{i}$ are usually monitored, especially for large machines like turbogenerators. Shaft deflection vector $s$ can be determined by introducing the necessary end conditions and solving the following equation (3) for a shaft:

$$
L=K_{s} s
$$

where $K_{s}$ is the stiffness matrix of the shaft and $L$ is the static load vector acting on it. $L$ contains all bearing reactions as well as the external static load. Shaft deflection vectors $S_{i}$ in each bearing $\left(i=1, \ldots, N_{B}\right)$, which are required in (2), are a subset of $s$. Bearing reactions $R_{i}$, which have to be included in $L$, can be determined from measured shaft eccentricity vectors $e_{i}$ in corresponding bearings by using the bearing static characteristics:

$$
R_{i}=R_{i}\left(e_{i}\right) \quad \text { for } i=1, \ldots, N_{B}
$$

Equations (1), in our method, are "additional" and we can use them to determine selected unknown parameters in the system. This gives us a choice of either measure less parameters (less than $N_{B}$ shaft eccentricity vectors $e_{i}$ ) or determine up to four unknown components of the static load. In this paper we consider the following three cases of alignment identification:

(1) Any $N_{B}-2$ out of $N_{B}$ shaft eccentricity vectors $e_{i}$ are measured (the minimum required)
(2) Any $N_{B}-1$ out of $N_{B}$ shaft eccentricity vectors $e_{i}$ are measured. This case enables to estimate 2 uncertain components of the static load.

(3) All $N_{B}$ shaft eccentricity vectors $e_{i}$ are measured. This case enables to estimate 4 uncertain components of the static load.

\subsection{Case 1: Measured $N_{B}-2$ Shaft Eccentricities}

The procedure of determining the alignment of the machine (positions of bearing axes) for this case is presented in the flow DIAGRAM 1.

This case represents the minimum necessary measurements and requires the exact static load distribution on the shaft. Accuracy of the alignment reconstruction will depend strongly on the accuracy of the estimation of the static load, in addition to the accuracy of the bearing characteristics.

\subsection{Case 2: Measured $N_{B}-1$ Shaft Eccentricities}

The procedure of determining the alignment of the machine (positions of bearing axes) for this case is presented in the flow DIAGRAM 2.

Since one more shaft eccentricity vector than the minimum required is available, we can also estimate two unknown or most uncertain components of the static load at the selected location(s) along the shaft.

If locations of uncertain static load components are well selected, accuracy of the alignment reconstruction will depend mainly on the accuracy of the bearing characteristics used to determine bearing reactions from bearing eccentricities.

\subsection{Case 3: Measured $N_{B}$ Shaft Eccentricities}

The procedure of determining the alignment of the machine (positions of bearing axes) for this case is presented in the flow DIAGRAM 3.

Since two more shaft eccentricity vectors than the minimum required are available, we can also estimate 


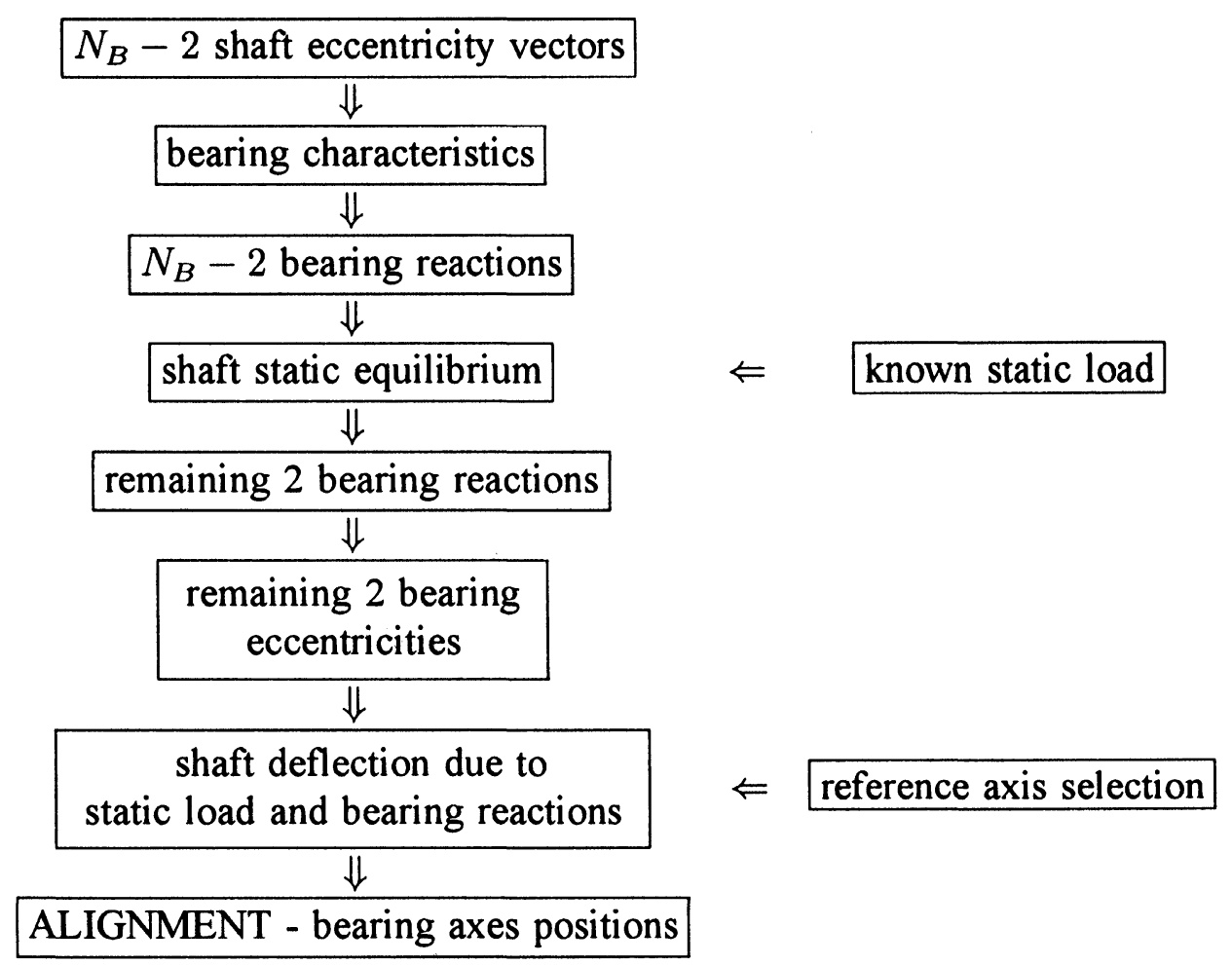

DIAGRAM 1 Flow diagram for case 1.

four unknown or most uncertain components of the static load at the selected locations along the shaft.

If locations of uncertain static load components are well selected, the accuracy of the alignment reconstruction will depend mainly on the accuracy of the bearing characteristics used to determine bearing reactions from bearing eccentricities.

\section{NUMERICAL VERIFICATION}

Verification of the method will be demonstrated on a numerical model of a vertical shaft machine. The shaft in this machine is supported in 3 hydrodynamic bearings. The rotor rotates at $1200 \mathrm{rpm}$ and it is subject to a transverse load.

\subsection{Rotor Model}

The rotor model was formulated using the FEM technique. Initial several hundred elements were condensed to give a 14 superelement model, having 15 nodes. Elastic properties of the rotor is characterized by the stiffness matrix $K_{s}$. The rotor may experience different temperature distribution, depending on ma'chine load and other operating parameters. Therefore, for each temperature distribution a separate rotor stiffness matrix should be formulated.

\subsection{Bearing Characteristics}

The considered machine has 3 pressurised hydrodynamic bearings. Each bearing geometry is different. Bearing characteristics have been determined using 


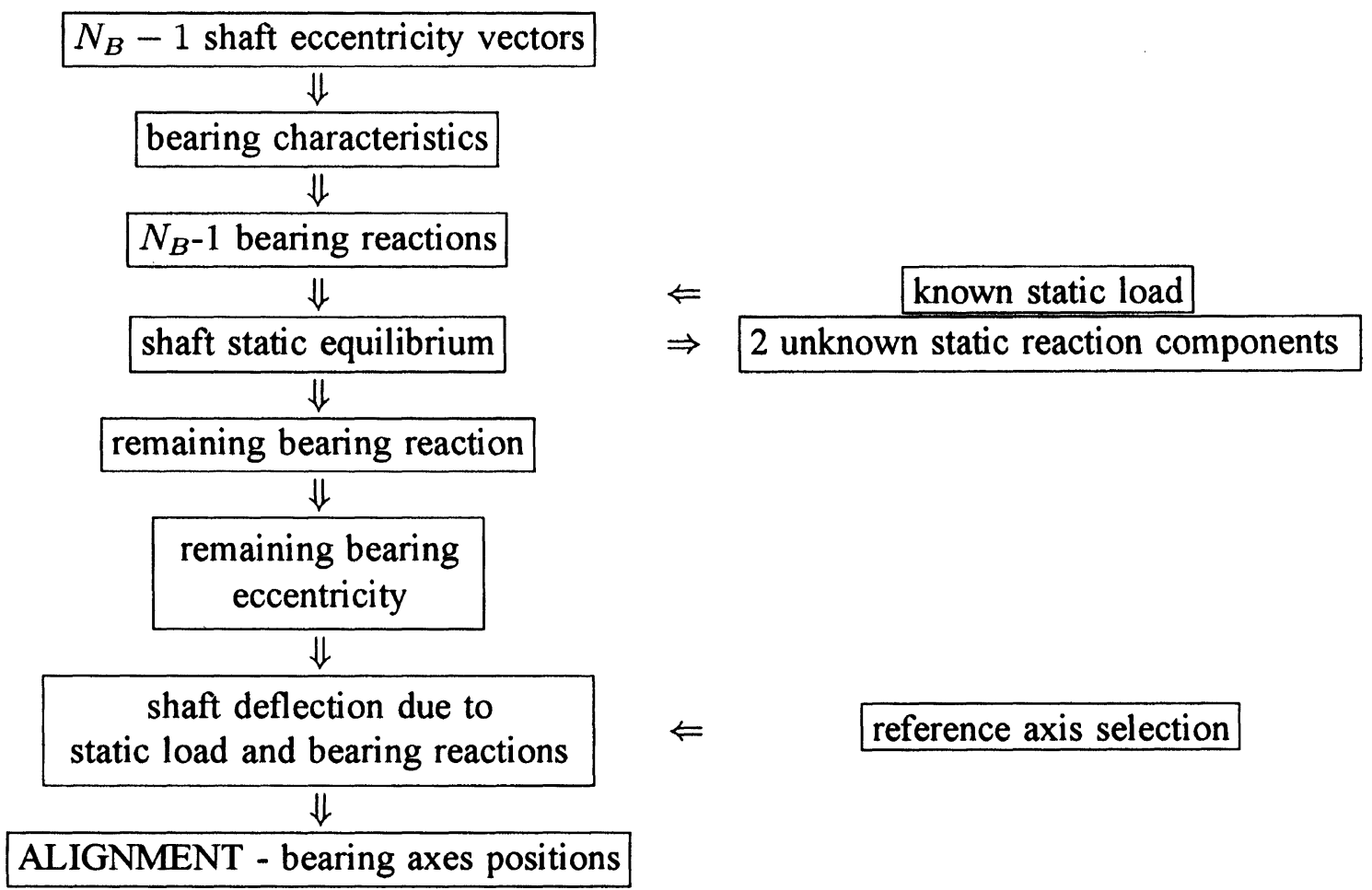

DIAGRAM 2 Flow diagram for case 2.

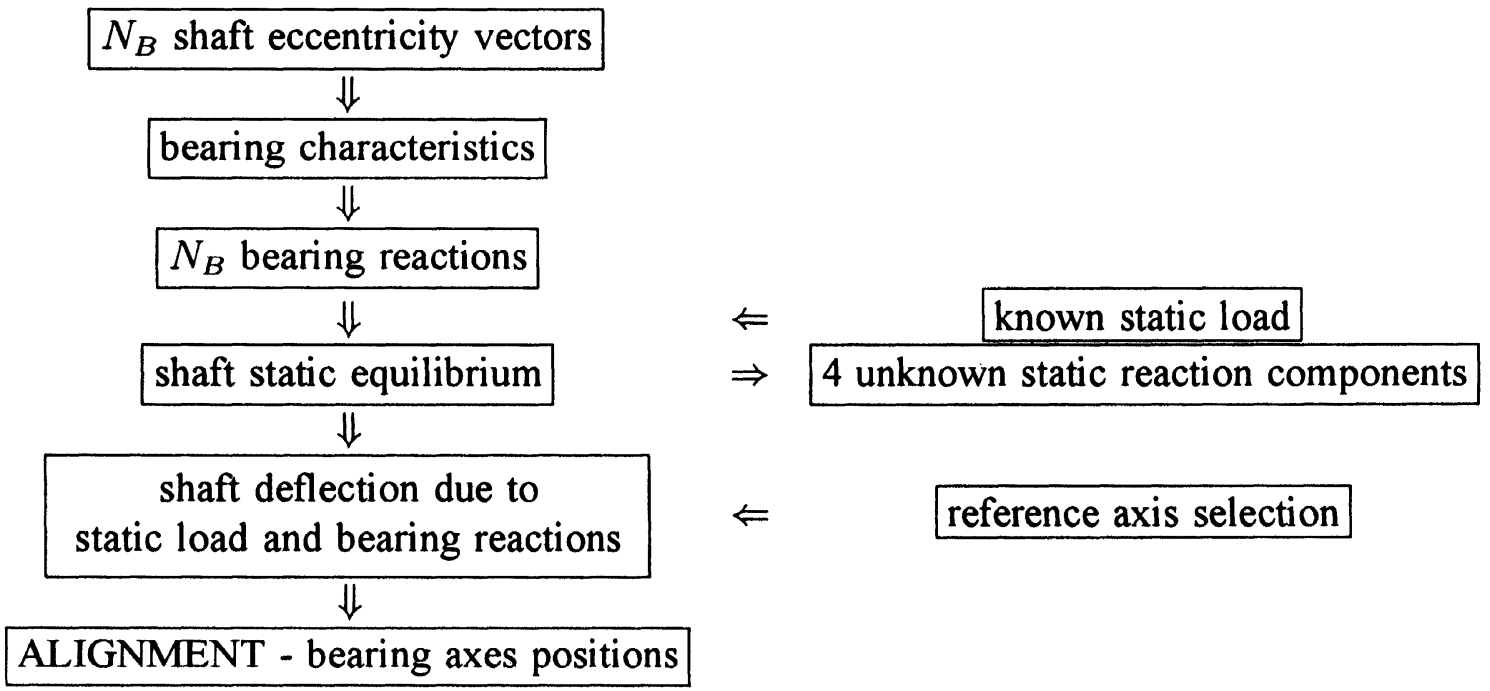

DIAGRAM 3 Flow diagram for case 3. 


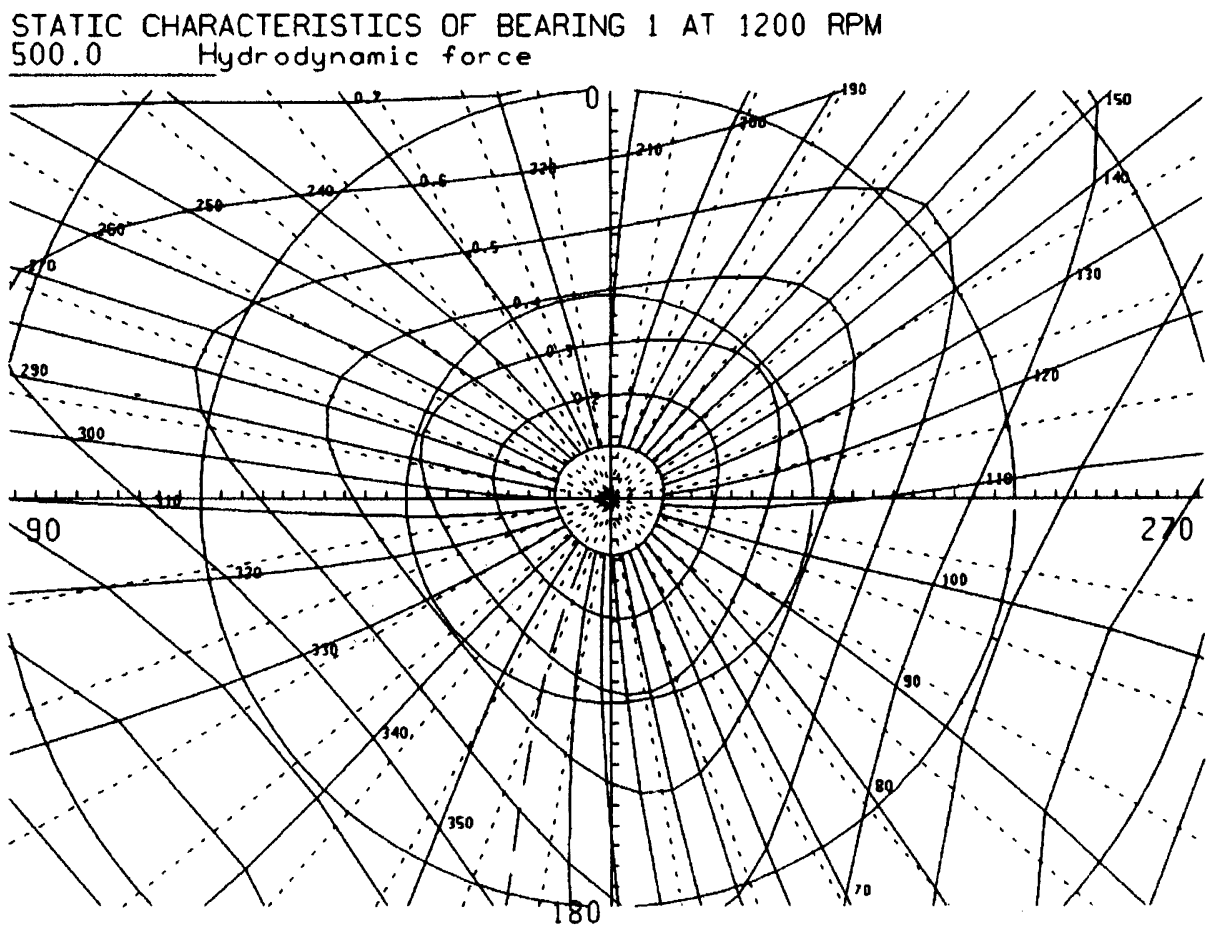

FIGURE 2 Static characteristics of bearing 1 .

specially developed computer models. Detailed description of bearing characteristics calculation ( $\mathrm{Li}$ [1990], Li and Chalko [1996]) is beyond the scope of this paper, however, a brief description of the algorithm is given below. We used the Optimized Finite Difference Method to solve the Reynold's Equation with appropriate boundary conditions, and approximate thermal effects for each bearing pad to determine the lubricant pressure distribution on each pad. Calculation was performed in 2-dimensional grid, giving circumferential as well as longitudinal pressure distributions. Bearing total hydrodynamic force has been then calculated by integrating pressures obtained from all pads. Obtained hydrodynamic bearing force vector $f_{h}$ is a function of journal position and velocity in the bearing as well as the journal angular velocity. Since the procedure of the alignment estimation requires only the static characteristics, we assumed all journal transverse velocities to be zero.
Static bearing characteristics for bearings 12 and 3 for the example system analysed here are presented in FIGURES 2, 3 and 4 respectively.

\subsection{Alignment Reconstruction}

For the test reported in this paper, we considered that the axis of the middle bearing is out of alignment with respect to the reference line connecting bearings 1 and 3, by the amount specified in TABLE I (approximately $220 \mu \mathrm{m}$ ). Then, we calculated the response of the system, for some randomly selected static load and the unbalance distribution. Results of these calculations are shown in FIGURES 5, 6 and 7. Specifically, the journal eccentricities in each bearing have been calculated as required by our method of alignment identification. 
STATIC CHARACTERISTICS OF BEARING 2 AT 1200.00 RPM

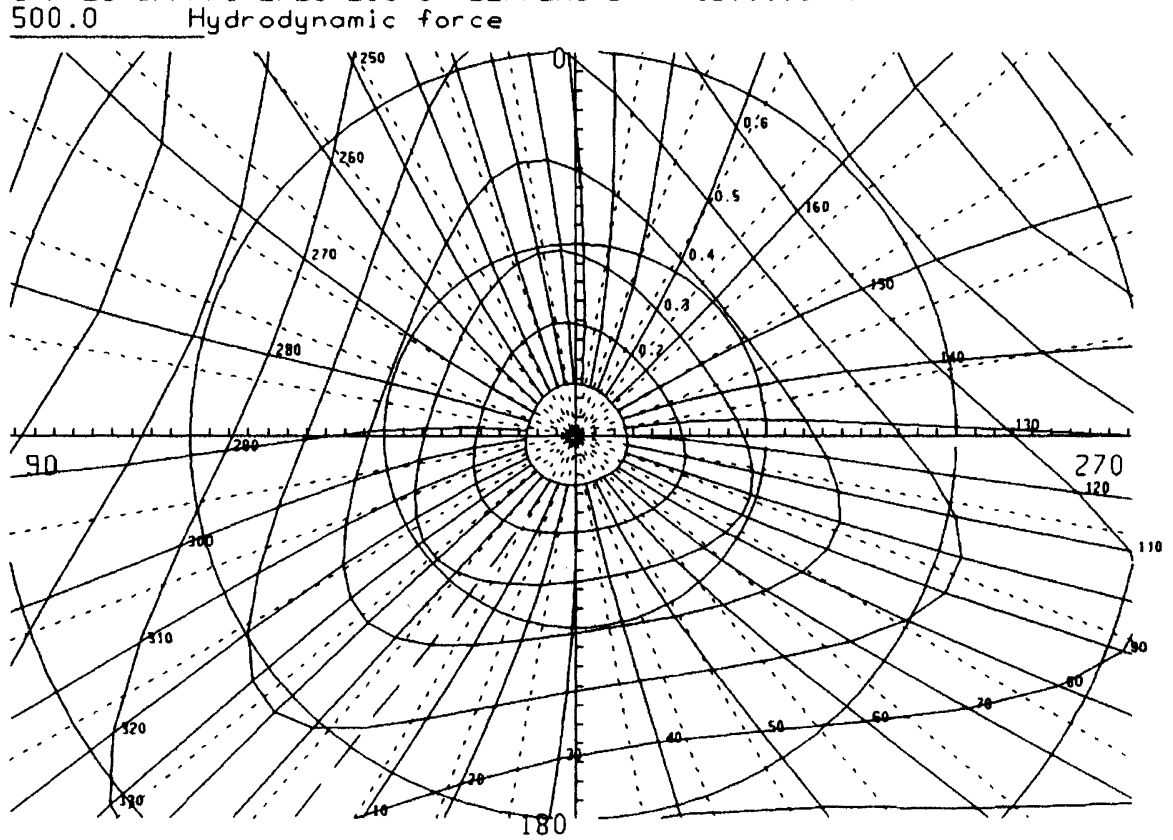

FIGURE 3 Static characteristics of bearing 2 .

STATIC CHARACTERISTICS OF BEARING 3 AT 1200.00 RPM 100.0 Hydrodynamic force

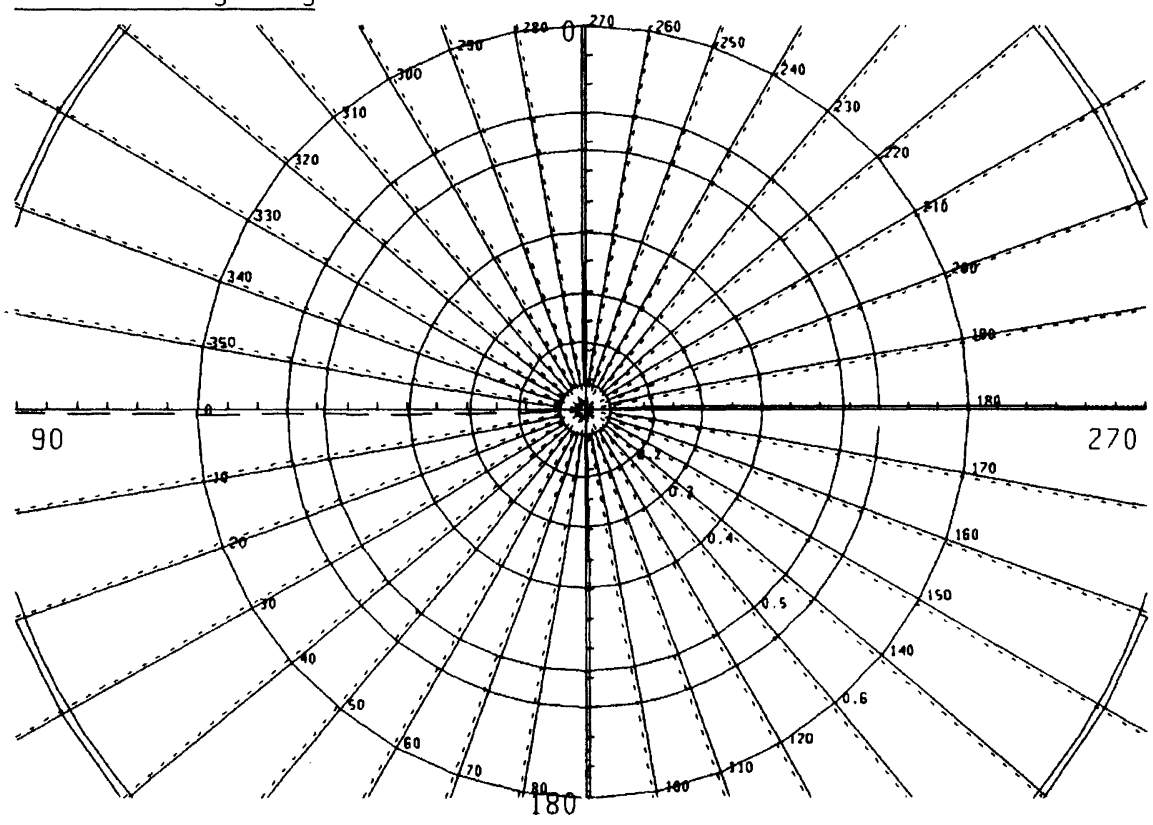

FIGURE 4 Static characteristics of bearing 3 . 
TABLE I Alignment Reconstruction Errors For Cases 1, 2 and 3.

\begin{tabular}{lccccc}
\hline caselvariable & vertical $[\mathrm{m}]$ & horiz $[\mathrm{m}]$ & error $[\mu \mathrm{m}]$ & residual static load node 7 [N] & residual static load node $14[\mathrm{~N}]$ \\
\hline original alignment of BRG2 & $-4.168 \mathrm{E}-05$ & $2.218 \mathrm{E}-04$ & & & \\
Case 1 $\left(N_{B}-2\right.$ eccentricities) & $-4.184 \mathrm{E}-05$ & $2.217 \mathrm{E}-04$ & 0.2 & 0.19 & 19 \\
Case 2 $\left(N_{B}-1\right.$ eccentricities) & $-4.181 \mathrm{E}-05$ & $2.217 \mathrm{E}-04$ & 0.2 & $1.700 \mathrm{E}-01$ & $1.000 \mathrm{E}-01$ \\
Case $3\left(N_{B}\right.$ eccentricities $)$ & $-4.159 \mathrm{E}-05$ & $2.218 \mathrm{E}-04$ & 0.09 & \\
\hline
\end{tabular}

Simulated eccentricities have then been used to reconstruct the misalignment of bearing 2 by applying the method outlined in this paper. Results are summarised in TABLE I. As it can be seen from TABLE $\mathrm{I}$, the system alignment has been reconstructed to micrometer accuracy. The residual static load, calculated in Cases 2 and 3 should be exactly zero, because we used the known static load to estimate the alignment. Non-zero values of the static load, which are negligible in our case, are caused by numerical errors.

\subsection{Accuracy of Alignment Reconstruction}

The accuracy of the alignment reconstructed using the method presented in this paper depends on:
(1) Accuracy of bearing characteristics. This accuracy is critical in the method. If possible, experimentally verified static characteristics should be used.

(2) Accuracy of shaft eccentricity measurements. If bearing characteristics are non-linear, small changes in eccentricity could correspond to significant changes in bearing reactions. Offset calibration for eccentricity sensors is essential.

(3) Accuracy of shaft modelling

(4) Accuracy of the determination of the transverse static load acting on the shaft

(5) Numerical accuracy of static equilibrium equations (1) and their solutions. This accuracy requires special attention for large machines like

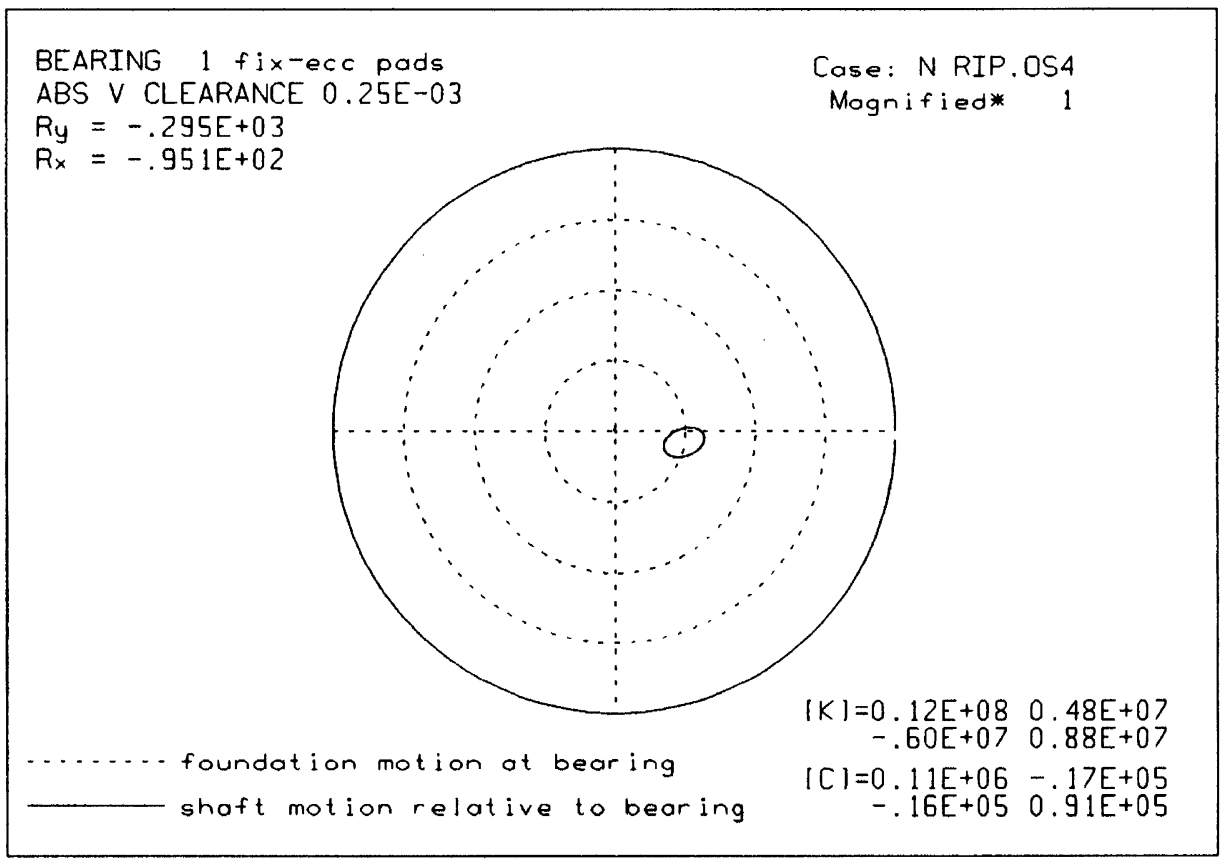

FIGURE 5 Simulated eccentricity in bearing 1 . 


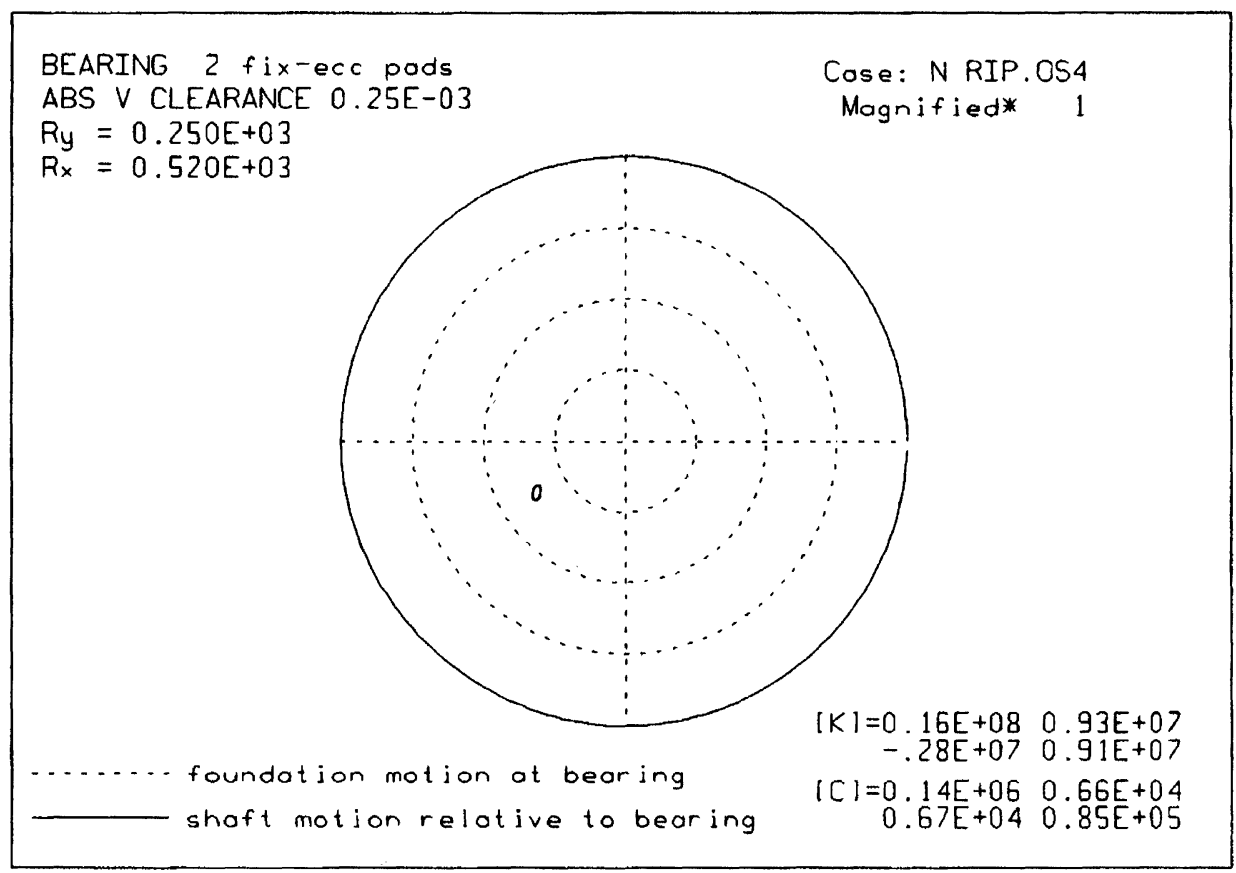

FIGURE 6 Simulated eccentricity in bearing 2 .

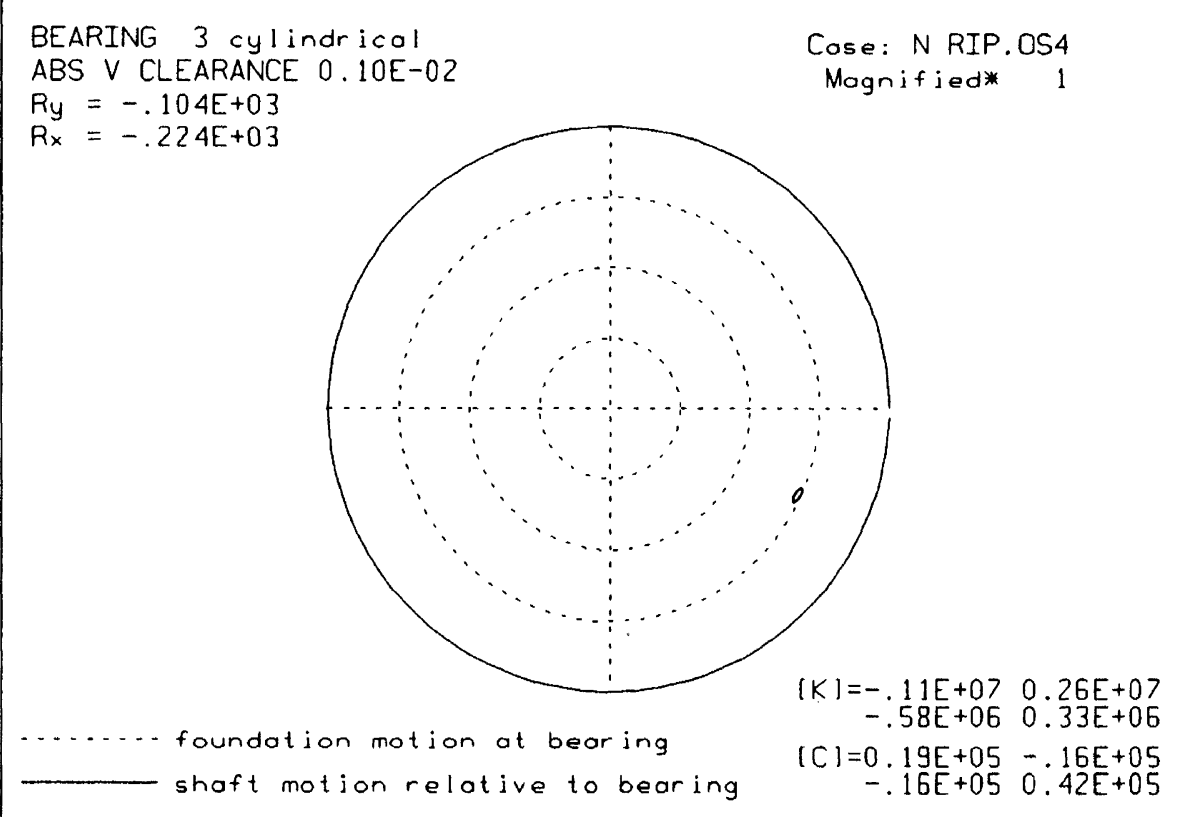

FIGURE 7 Simulated eccentricity in bearing 3 . 
turbogenerators, where the distributed static load from gravity forces is of the order of hundreds of tonnes. In such case, a special attention should be given to calculations of the sum of all moments and forces so that the round-off errors are minimised and the required precision is maintained.

\section{CONCLUSIONS}

(1) Presented methods enables machine bearing alignment identification on the basis of

(a) measured shaft eccentricities at bearings

(b) knowledge of the transverse static load on the shaft

(2) The method requires accurate numerical models for the rotor and all bearings.

(3) The accuracy of bearing models (bearing characteristics) is critical to the accuracy of the method

(4) The method does not put any restrictions on the type of bearings, providing that sufficiently accurate bearing characteristics are available.

(5) Uncertain static load components acting on the shaft in the transverse direction could be estimated in addition to alignment estimation

(6) Practical application of the method was demonstrated for a vertical rotor supported in 3 hydrodynamic bearings. For this system, alignment was determined with micrometer accuracy, thereby confirming the practical applicability of the method.

(7) In the presented example, the accuracy of the alignment reconstruction was best, when shaft eccentricities in all bearings have been measured.

\section{Acknowledgments}

Methods presented in this paper have been developed in cooperation with Toshiba Corporation, Nuclear Engineering Laboratory.

\section{References}

Chalko T.J., Li D.X., 1993, "Modelling Vibration of a Large Turbine-Generator Set-Effects of Alignment" Proceedings of JSME-ASME International Conference on Power Engineering (ICOPE93) Tokyo, Japan, Sept 12-16 1993, pp6.

Chalko T.J., Li D.X., 1995, "Modelling Turbine Vibration in Terms of its Load Variation," International Journal of Rotating Machinery, Vol. 9, 1995

Chalko T.J., Li D.X., 1996, "Bearing Alignment Estimation in Rotating Machinery", Proc. 6th International Symposium on Transport Phenomena and Dynamics of Rotating Machinery (ISROMAC-6), Hawaii, Feb 1996, p. 68-77.

Ding J., 1993, "Identification of Multi-bearing Rotor System Configuration", PhD Thesis, The University of Melbourne, Department of Mechanical and Manufacturing Engineering

Hashemi, Y., 1983, "Alignment Changes and Their Effects on the Operation and Integrity of Large Turbine Generators: Experience in the CEGB South Eastern Region," Steam and Gas Turbine Foundations and Shaft Alignment-IMechE Conference Publications, February 1983, pp. 19-30.

Hori, Y., and Uematsu, R., 1980, "Influence of Misalignment of Support Journal Bearings on Stability of a Multi-Rotor System," Tribology International, Vol. 13, No. 5, p. 249.

Krodkiewski, J.M., Ding J., Zhang N., 1994, "Identification of unbalance change using a nonlinear mathematical model for multibearing rotor system" Journal of Sound and Vibration, Vol. 169 p 685-698.

Li, D.X., 1990, "Dynamic Optimization of Multi-Bearing Rotors in Terms of System Configuration Parameters", PhD thesis, Department of Mechanical Engineering, University of Melbourne, Australia.

Li, D.X., Chalko T.J., 1996, "Hydrodynamic Characteristics of Combination Pad Journal Bearing", Proc. 6-th International Symposium on Transport Phenomena and Dynamics of Rotating Machinery (ISROMAC-6), Hawaii, Feb. 1996, p 679-687

Parszewski, Z.A., Chalko, T.J., and Li, D.X., 1988a, "Dynamic Optimization of Machine Systems Configuration" Ghapter in Structural Optimization, Kulwer Academic Publishers, pp. 217224.

Parszewski, Z.A., Chalko, T.J., and Li, D.X., 1988b, "Turbogenerator Layout for Optimal Dynamic Response-a study and a case history", IMechE paper C250/88, pp. 427-434.

Parszewski, Z.A., Krodkiewski, J.M., 1986, "Machine Dynamics in Terms of the System Configuration Parameters," Proc. International Conference on Rotor Dynamics, Tokyo, Japan, September 14-17, pp. 239-244.

TURBINE-PAK Theoretical Manual, 1992, Scientific Engineering Research, Melbourne, Australia pp 146.

Webster, E., and Gibson, K.S., 1977, "Turbine Monitoring-Experience in CEGB Southeastern Region," I.Mech.E. Conference on Turbine Monitoring, C243/77 


\section{ait \\ ENERGY MATERIALS}

M A N E Y publishing

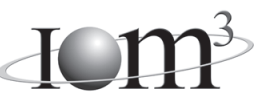

\section{Materials Science \& Engineering for Energy Systems}

Maney Publishing on behalf of the Institute of Materials, Minerals and Mining

The Institute of Materials, Minerals \& Mining

Economic and environmental factors are creating ever greater pressures for the efficient generation, transmission and use of energy. Materials developments are crucial to progress in all these areas: to innovation in design; to extending lifetime and maintenance intervals; and to successful operation in more demanding environments. Drawing together the broad community with interests in these areas, Energy Materials addresses materials needs in future energy generation, transmission, utilisation, conservation and storage. The journal covers thermal generation and gas turbines; renewable power (wind, wave, tidal, hydro, solar and geothermal); fuel cells (low and high temperature); materials issues relevant to biomass and biotechnology; nuclear power generation (fission and fusion); hydrogen generation and storage in the context of the 'hydrogen economy'; and the transmission and storage of the energy produced.

As well as publishing high-quality peer-reviewed research, Energy Materials promotes discussion of issues common to all sectors, through commissioned reviews and commentaries. The journal includes coverage of energy economics and policy, and broader social issues, since the political and legislative context influence research and investment decisions.

\section{CALL FOR PAPERS}

Contributions to the journal should be submitted online at http://ema.edmgr.com

To view the Notes for Contributors please visit: www.maney.co.uk/journals/notes/ema

Upon publication in 2006, this journal will be available via the Ingenta Connect journals service. To view free sample content online visit: www.ingentaconnect.com/content/maney

For further information please contact:

Maney Publishing UK

Tel: +44 (0)113 2497481 Fax: +44 (0)1132486983 Email: subscriptions@maney.co.uk

or

Maney Publishing North America

Tel (toll free): 8662975154 Fax: 6173546875 Email: maney@maneyusa.com

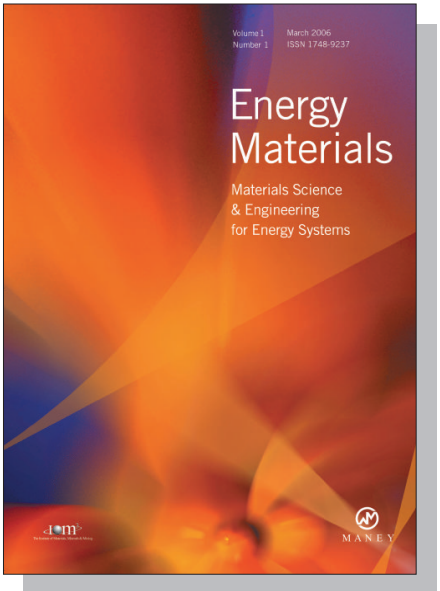

EDITORS

Dr Fujio Abe

NIMS, Japan

Dr John Hald, IPL-MPT, Technical University of Denmark, Denmark

Dr R Viswanathan, EPRI, USA

\section{SUBSCRIPTION INFORMATION}

Volume 1 (2006), 4 issues per year

Print ISSN: 1748-9237 Online ISSN: 1748-9245

Individual rate: $£ 76.00 / U S \$ 141.00$

Institutional rate: $£ 235.00 /$ US $\$ 435.00$

Online-only institutional rate: $£ 199.00 / U S \$ 367.00$

For special $\mathrm{IOM}^{3}$ member rates please email

subscriptions@maney.co.uk

\section{For further information or to subscribe online please visit www.maney.co.uk}



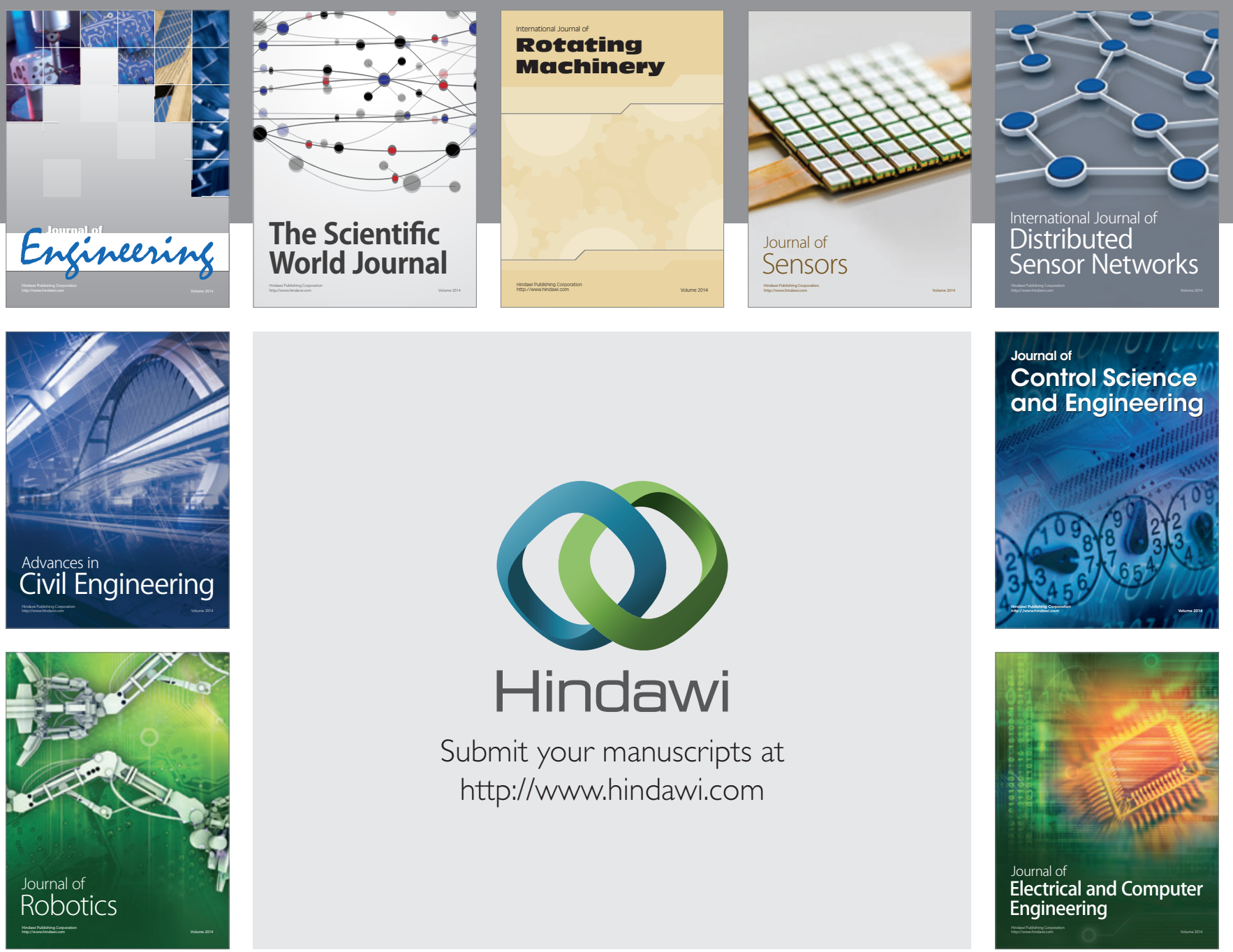

Submit your manuscripts at

http://www.hindawi.com
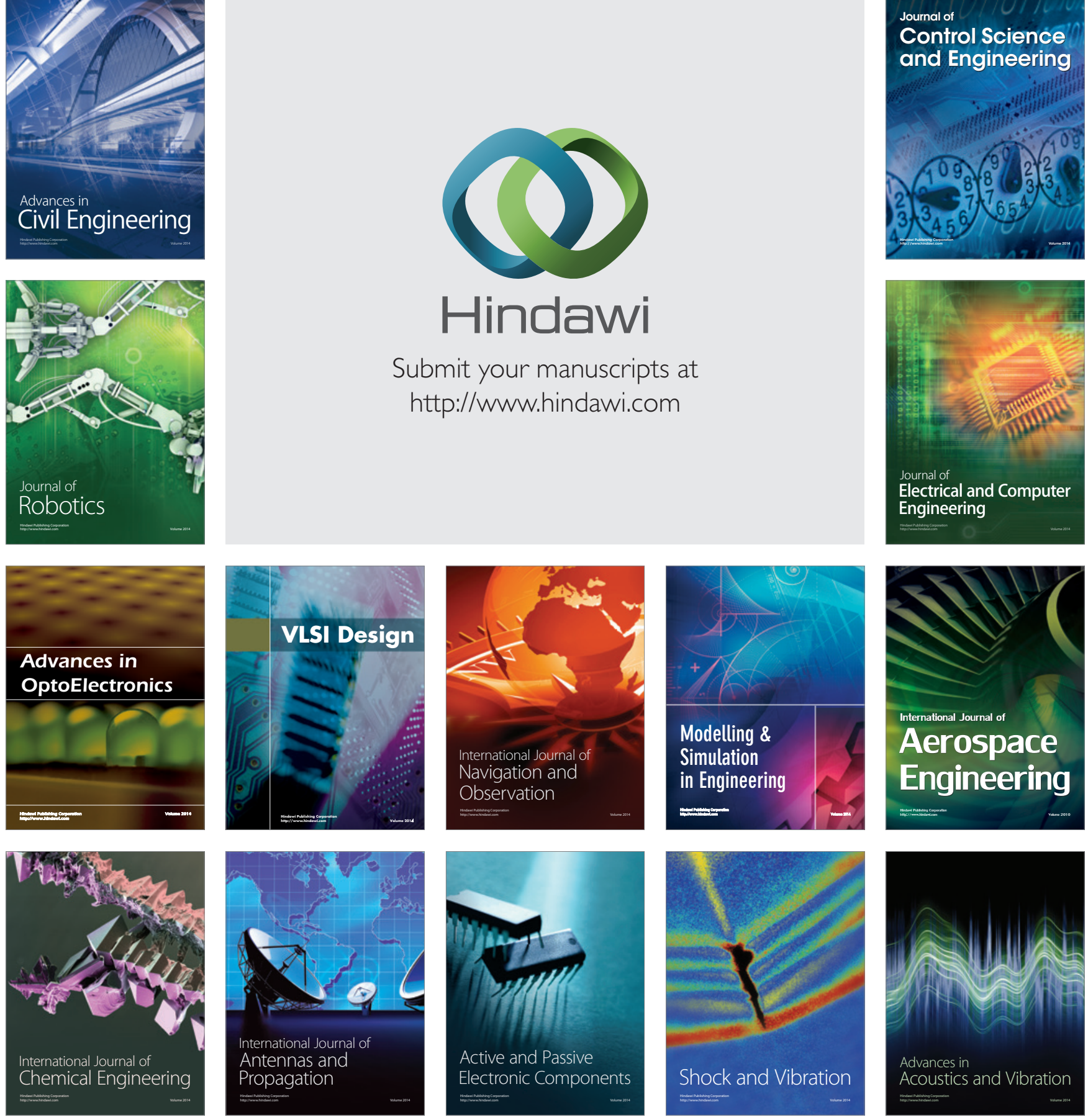